\title{
37. Anoecia karatanei, a new Gall-producing Aphid.
}

\author{
By Chujiro SASAKI, M.I.A. \\ (Comm. April 13, 1936.)
}

On examination of some leaf buds of the Karatane-Ogatamanoki, Magnolia fuscata, at the end of April in 1930, I discovered a few nymphs of wingless viviparous female, which produce slight depressions on the outer side of leaves. With the growth of the bud the depression becomes gradually deeper and broader so as to form a yellowish green gall (Fig. 1) which is hemispherical in the outer and conical in the inner half, presenting at the narrow end a minute opening left after the intrusion of the nymph. Not only does the gall in the full grown stage assume a colour of crimson red in the outer and of pink in the inner half, but it loses altogether its opening at the narrow end. Within the gall the nymph develops into the wingless viviparous female, which produces some larvae. The larva, after moulting twice, develops into the nymph and in turn into the winged viviparous female. Passing through the opening at the narrow end of the gall, the winged female flies about and appears to lay some larvae on twigs or winter buds. Though not clearly made out, the larva passes winter on trichomes, and develops into the wingless viviparous female in the following spring.

So far as I can learn, the aphid in question appears to represent a new species. Giving the name of Anoecia karatanei to this, I would here put on record its various stages.

Winged viviparous female (Fig. 2).-Head and eyes black, with an ocular tubercle. Antennae fuscous, short, composed of five joints, of which the basal two are $0.005 \mathrm{~mm}$., the third $0.063 \mathrm{~mm}$., the fourth $0.75 \mathrm{~mm}$., and the fifth $0.015 \mathrm{~mm}$. in length. Last three joints generally marked with ten, six and seven ring markings respectively. Fifth joint of a conical shape, beset with three bristles. Rostrum $0.13 \mathrm{~mm}$. long, extending to the base of the first paired legs. Thorax dull orange with an almost square brownish marking on the mesothorax, a brownish spot at the base of the fore wings and two short bands at the hind part of the thorax. Fore wings fuscous, $1.60 \mathrm{~mm}$. long by $1.22 \mathrm{~mm}$. broad; stigma dark grey. Radius stout; subcosta and media running just above and below the radius respectively, indicated simply by faint lines. A branch of media bifurcated ; two branches of cubitus close to the basal part of media so as to suggest that they are connected with the media. Hind wing $1.25 \mathrm{~mm}$. long by $0.35 \mathrm{~mm}$. broad. Legs dark grey, having two tarsi with two claws and two pairs of digitules, of which a pair is longer than the other. Abdomen greyish orange, pale on the ventral side ; cornicles rudimentary, indicated simply by a ring marking. Length of body $1 \mathrm{~mm}$. Expanse of wings $3 \mathrm{~mm}$.

Eggs. - Light orange yellow, elongate-oval, $0.26 \mathrm{~mm}$. long by $0.10 \mathrm{~mm}$. broad.

First instar larva.-Body light orange yellow, furnished on the lateral sides of the thorax and abdomen with short cylindrical tubes 
secreting white waxy filaments. Ocelli crimson red, three on the black disc on each side of the head. Antennae composed of three joints, of which the basal two are short and stout, and the terminal is elongatecylindrical and bears three bristles at the tip. Legs stout, with two claws and two digitules at the end. Mature larva $0.355 \mathrm{~mm}$. long by $0.155 \mathrm{~mm}$. broad.

Nymph of wingless viviparous female.-Body dull greyish yellow; thorax yellowish brown; ocelli black, three. Antennae dark brown, consisting of three joints, of which the basal two are short and stout, and the terminal is elongate-cylindrical with imperfect ring markings and three bristles at the end.

Wingless viviparous female (Fig. 3).- - Head deep orange yellow; thorax and abdomen light orange yellow. Abdomen covered with white cottony secretions on the lateral sides. Antennae fuscous, composed of three joints, of which the basal two are short and stout, and the terminal is fairly long, marked with transverse wavy lines and beset with bristles at the tip. Ocelli crimson red, three on the triangular black disc on each side of the head. Legs pale yellow, with two tarsi, of which one is very small, and the other is pretty long and bears two claws and three digitules. Length $1.50 \mathrm{~mm}$., breadth $1.34 \mathrm{~mm}$.

Larva laid by wingless viviparous female.-Body of the first instar larva pale orange yellow, long, nearly spindle-shaped, more


Fig. 1. Outer (a) and inner (b) half of galls.

Fig. 2. Winged viviparous female.

Fig. 3. Wingless viviparous female. or less flattened, covered sparsely with fine hairs. Antennae composed of three joints, of which the basal two are fairly shorter than the terminal. Ocelli crimson red, three on the black disc on each side of the head. Legs light greenish yellow, with two claws and four digitules.

Body of the second instar larva long, spindle-shaped; head fuscous; thorax and abdomen pale orange yellow, with cottony secretions on the latter. Antennae and ocelli much as in the preceding stage.

Nymph. - Head white, exclusive of the pale orange hind part; thorax and abdomen pale orange, with a pair of white broad longitudinal bands on the mesothorax. Antennae short and stout, composed of four joints, of which the basal two are shorter than the third joint with imperfect ring markings, and the fourth joint is very small and bears three bristles. Wing-sheath and legs greyish white, the latter having two tarsi with two claws and two digitules. Abdomen dilated by the development of eggs. Length $1.33 \mathrm{~mm}$.; breadth $0.70 \mathrm{~mm}$. 